\title{
Association between Body Composition and Motor Performance in Preschool Children
}

\author{
Tanja H. Kakebeeke ${ }^{a}$ b Stefano Lanzic Annina E. Zysset ${ }^{a} \quad$ Amar Arhab $^{c}$ \\ Nadine Messerli-Bürgy ${ }^{c, d}$ Kerstin Stuelb $^{d}$ Claudia S. Leeger-Aschmann ${ }^{e}$ \\ Einat A. Schmutz ${ }^{e}$ Andrea H. Meyer ${ }^{f}$ Susi Kriemler ${ }^{e}$ Simone Munsch ${ }^{d}$ \\ Oskar G. Jenni ${ }^{a}$ b Jardena J. Puder ${ }^{c, g}$ \\ a Child Development Center, University Children's Hospital Zurich, Zurich, \\ Switzerland; ${ }^{b}$ Children's Research Center, University Children's Hospital Zurich, Zurich, \\ Switzerland; ' CService of Endocrinology, Diabetes \& Metabolism, Lausanne University \\ Hospital, Lausanne, Switzerland; d Department of Clinical Psychology and Psychotherapy, \\ University of Fribourg, Fribourg, Switzerland; e Epidemiology, Biostatistics and Prevention \\ Institute, University of Zurich, Zurich, Switzerland; ${ }^{f}$ Department of Psychology, University \\ of Basel, Basel, Switzerland; 9Service of Pediatric Endocrinology, Diabetology and Obesity, \\ Lausanne University Hospital, Lausanne, Switzerland
}

Keywords

Zurich Neuromotor Assessment · Body composition · Motor skills · BMI · SPLASHY

\section{Abstract}

Objective: Being overweight makes physical movement more difficult. Our aim was to investigate the association between body composition and motor performance in preschool children. Methods: A total of 476 predominantly normal-weight preschool children (age $3.9 \pm$ 0.7 years; m/f: 251/225; BMI $16.0 \pm 1.4 \mathrm{~kg} / \mathrm{m}^{2}$ ) participated in the Swiss Preschoolers' Health Study (SPLASHY). Body composition assessments included skinfold thickness, waist circumference (WC), and BMI. The Zurich Neuromotor Assessment (ZNA) was used to assess gross and fine motor tasks. Results: After adjustment for age, sex, socioeconomic status, sociocultural characteristics, and physical activity (assessed with accelerometers), skinfold thickness and WC were both inversely correlated with jumping sideward (gross motor task $\beta$-coefficient

Tanja H. Kakebeeke and Stefano Lanzi contributed equally to this paper as first authors; Oskar G. Jenni and Jardena J. Puder contributed equally as last authors.

Prof. Dr. Tanja H. Kakebeeke

Child Development Center

University Children's Hospital Zurich

Steinwiesstrasse 75, 8032 Zurich, Switzerland

tanja.kakebeeke@ kispi.uzh.ch 
Kakebeeke et al.: Association between Body Composition and Motor Performance in Preschool Children

$-1.92, p=0.027$; and $-3.34, p=0.014$, respectively), while BMI was positively correlated with running performance (gross motor task $\beta$-coefficient 9.12, $p=0.001$ ). No significant associations were found between body composition measures and fine motor tasks. Conclusion: The inverse associations between skinfold thickness or WC and jumping sideward indicates that children with high fat mass may be less proficient in certain gross motor tasks. The positive association between BMI and running suggests that BMI might be an indicator of fatfree (i.e., muscle) mass in predominately normal-weight preschool children.

(C) 2017 The Author(s)

Published by S. Karger $\mathrm{GmbH}$, Freiburg

\section{Introduction}

According to the dynamic system theory perspective, motor skill development is based on the complex interaction between task, organism, and environment [1]. The evolution of motor skills in any particular case depends on the difficulty of the tasks, the affordances and opportunities of the environment, and the physical and psychological properties of the child. Thus, the specific constraints of task, child, and environment have to be taken into account when studying motor development in children. For instance, a visually or auditory impaired child receives less stimulation and, thus, will be impaired in his motor skill development [2, 3]. The same may be true for an overweight child for whom the challenges of skipping, running, and balancing are certainly greater than for the normal-weight individual. In other words, antigravity activities are more difficult for an overweight than for a normal-weight child [4, 5]. In addition, it has been shown that obesity leads to decreased physical activity in children [6]. This is relevant because a child with many opportunities for physical activity will be more skilled in certain tasks as a result of more frequent practice [7-10], suggesting that active children are likely to be better motor performers than inactive individuals [11]. Moreover, a child with superior motor competence is more inclined to be more physically active in the future and thus is less at risk for further obesity than a child with poor motor skills [12].

In this study, we examined the effect of body composition on motor performance in preschool children using the Zurich Neuromotor Assessment (ZNA), a motor test designed to study the motor development of children $[13,14]$. We not only included the BMI but also skinfold thickness and waist circumference (WC) as body composition measures. In fact, a child with more muscle (i.e., fat-free mass (FFM)) and less fat mass (FM) has an advantage in motor skills over a child with less FFM and more FM, even if both children have the same BMI. More FM poses a greater challenge for the performance of gross motor skills such as hopping, skipping, and jumping than for fine motor exercises.

There is no single universally recommended method for the assessment of body composition of young children which is non-invasive and fulfils all research purposes [15]. The BMI $[16,17]$, widely used and easy to apply, is not a straightforward index because typical BMI values change with growth $[15,18]$. Additionally, children with a high proportion of FFM will have higher BMI values, mostly still within the normal-weight range. Skinfold thickness [19] and WC [20] are clinical measures closely related to body fatness in young children [15, 21, 22]. Currently, no data are available on the impact of different body composition measures on motor performance in young children.

The association between body composition and motor performance in children between 2 and 6 years is investigated in this study using three simple assessments for body composition: BMI, skinfold thickness, and WC. Because age, sex, socioeconomic status (SES) [23], sociocultural differences [24], and physical activity [10,11,25] are all expected to be predictive of motor performance in children, these factors are incorporated as covariates in the analysis. 
Kakebeeke et al.: Association between Body Composition and Motor Performance in Preschool Children

\section{Participants and Methods}

\section{Participants}

A total of 476 preschool children (mean age $3.9 \pm 0.7$ years; $\mathrm{m} / \mathrm{f}: 251 / 225$ ) participated in a national cohort study, the Swiss Preschoolers' Health Study (SPLASHY). They were recruited at child care centers in five cantons of Switzerland (Aargau, Berne, Fribourg, Vaud, Zurich). The child care centers were classified as from either an urban or a rural community and as of either low or high SES. Of the original 639 contacted child care centers, 84 were willing to participate. Parents were contacted through child care centers during the recruitment period from February 2014 to November 2014. Only the parents of the children who were unable to perform the test (e.g. due to motor handicap) were not asked for their children to participate. Each child was assessed at his or her child care center on a single afternoon (for details see the study protocol [26]), and parents were asked to complete several questionnaires concerning their child's health and environment. The study was approved by the local ethical committees and conducted in accordance with the Declaration of Helsinki.

\section{Procedure}

Subjects were tested in the child care center. First, they underwent body composition assessments; thereafter, motor performance was tested. Children were tested one by one in a separate room with the researcher and an educator from the child care center on one afternoon. The three different body composition measures (BMI, skinfold thickness, and WC) were always measured by the same researcher in each center (AA, AZ, KS, CL, ES), and these were all trained by one medical doctor (JP). The motor assessment was performed by the same experimenters, who were all trained by one neurophysiologist (TK). Motor tests were recorded on digital video, and scoring of the videos took place offline subsequently. After the medical and motor assessments, the children received a present and a stamp on their hand as a reward for participation.

\section{Assessments of Body Composition Measures}

Height was measured to the nearest $0.1 \mathrm{~cm}$ with a stadiometer while the child stood with their back to a wall, and weight was measured to the nearest $0.1 \mathrm{~kg}$ using a scale (Seca, Basel, Switzerland). BMI was then calculated as weight / height squared $\left(\mathrm{kg} / \mathrm{m}^{2}\right)$. BMI percentiles were calculated, and overweight/obesity was identified according to the definitions of the WHO [17] and of the International Obesity Task Force [17, 27]. Skinfold thickness was measured in triplicate to the nearest $0.1 \mathrm{~mm}$ at the triceps, biceps, subscapular crest, and suprailiac crest with Harpenden calipers (HSK-BI, British Indicators, Weybridge, UK) [16]. The mean of the three measurements of each skinfold thickness was then used for calculation. The sum of all four mean skinfold thickness measurements was calculated; this sum is subsequently referred to as 'skinfold thickness'. WC was measured twice over the belly of the child between the iliac crest and the lowest border of the rib cage to the nearest $0.1 \mathrm{~cm}$ with a flexible tape, and the mean of the two measures was used for calculation [20].

\section{Motor Performance Measured with the ZNA}

The ZNA is a standardized procedure for assessing the speed of several motor tasks (timed performance) and the quality of movements [14, 28-30]. For the ZNA3-5, which has been developed for 3- to 5-year-old children, we used essentially the same items as in the ZNA5-18 but adapted them for younger children (e.g., fewer repetitions). The researcher explained verbally how to do the tasks and then demonstrated it. If the child did not understand the task and did something different from what was demonstrated, demonstrations and explanations were repeated. If he still could not complete the task, the examiner scored the task as 'failed' and continued with another item.

\section{Fine Motor Skills}

Handedness was determined by letting the child perform three one-handed tasks. The hand used for the majority of the tasks was identified as the dominant hand.

Task 1: Filling in a pegboard (12 pins) with dominant and non-dominant hand - adaptive motor task

The child sat at a table with the lower arm parallel to the table; the feet were always on the ground with knees and ankle flexed to $90^{\circ}$. The task was performed one hand after the other, always dominant first. For tasks that were timed, the child was asked to complete the task as quickly as possible. One hand rested on the board while the other hand put the pegs in the holes. The examiner demonstrated how to put the peg into the hole, but no practice attempt was given. The stopwatch was started when the child touched the first peg and was stopped when the child released the last peg. 
Kakebeeke et al.: Association between Body Composition and Motor Performance in Preschool Children

Tasks 2-5: Repetitive and alternating movements of the hands and repetitive and sequential movements of the fingers with dominant and non-dominant hand - pure motor skills

Children performed these tasks sitting on a chair with hips, knees, and feet at a $90^{\circ}$ angle, hands on the knees or held up in the air, and abduction in the shoulder of $70-90^{\circ}$. The examiner gave verbal instructions while demonstrating the task. No practice trials were given. The following motor tasks with dominant and non-dominant hand were performed: 10 repetitive hand movements, 5 alternating hand pro- and supination, 10 repetitive finger movements, and 2 sequential finger movements. Time was taken in tenths of seconds. For the sequential finger movements, we created a five-point scale from 0 (perfect) to 4 (not possible), as this task was too difficult for the child so that we could not take time.

Gross Motor Skills

The side dominance of the upper extremities was also applied to the lower extremities, as was the order of testing: it was always started with the dominant side.

Task 6-10: Standing on one leg with dominant and non-dominant leg - static balance; walking on a straight line, hopping on one leg (dominant and non-dominant), jumping sideward, running - dynamic balance

The gross motor skills were all assessed with ordinal scales. An exact description is given in table 1.

SES

SES was calculated by coding the occupational status of both parents and transforming this into an International Socio-Economic Index (ISEI) value [31]. The maximal SES was then determined by the selection of the highest of the maternal and paternal ISEI values.

\section{Sociocultural Differences}

This study took place in two of Switzerland's sociocultural areas, the German-speaking region and the French-speaking region. The participating child care centers were situated in five cantons which together cover up to $50 \%$ of the Swiss population.

\section{Physical Activity as Measured with Accelerometers}

Physical activity was monitored with an accelerometer (MTI/CSA GT3X+; Actigraph, Shalimar, FL, USA), which children were asked to wear around the hip continuously for 5 weekdays and 2 weekend days. The data for a day were considered valid for analysis when at least $10 \mathrm{~h}$ of recordings were available. We analyzed mean total physical activity in all children with at least one valid day using 60 -second epochs. The device was removed for water-based activities (swimming and showering), and night measurements (recordings between $9 \mathrm{pm}$ and $7 \mathrm{am}$ ) were excluded).

\section{Statistical Analyses}

Descriptive statistics were calculated by means \pm standard deviations (SD) for continuous variables and by frequencies and percentages for categorical variables. A multilevel model (i.e., the child and child care center were the two hierarchical levels) including a random intercept was used to assess the associations between motor performance and body composition. Predictors were BMI, skinfold thickness, and WC (i.e., the three different measures of body composition), and outcomes were the different motor performance components of the ZNA.

Analyses for the ZNA were based on standard deviation scores (SDS). SDS of timed performance were then summarized into standard components (for details see [32, 33]).

SDS for pegboard task with dominant and non-dominant hand were summarized into the pegboard component. SDS of repetitive and alternating movements of the hands and repetitive and sequential movements of the fingers with dominant and non-dominant hand were summarized into the pure motor skills component. SDS for the static balance task with dominant and non-dominant leg were summarized into the static balance component, and SDS of the four dynamic tasks (walking in a straight line, side-to-side jumping, hopping on one leg, and running) were summarized into the dynamic balance component. We also performed multilevel analyses between body composition measures and individual items of the ZNA, such as walking in a straight line, jumping sideward, hopping on one leg and running (SDS data) to investigate the association with each parameter of the dynamic balance testing battery.

Multilevel model analyses were adjusted for children's age and sex, parental ISEI, sociocultural region of Switzerland (German- or French-speaking), and total physical activity, as we expected these to be predictive of the motor performance components of the ZNA. Separate analyses were run for each predictor by outcome 
Kakebeeke et al.: Association between Body Composition and Motor Performance in Preschool Children

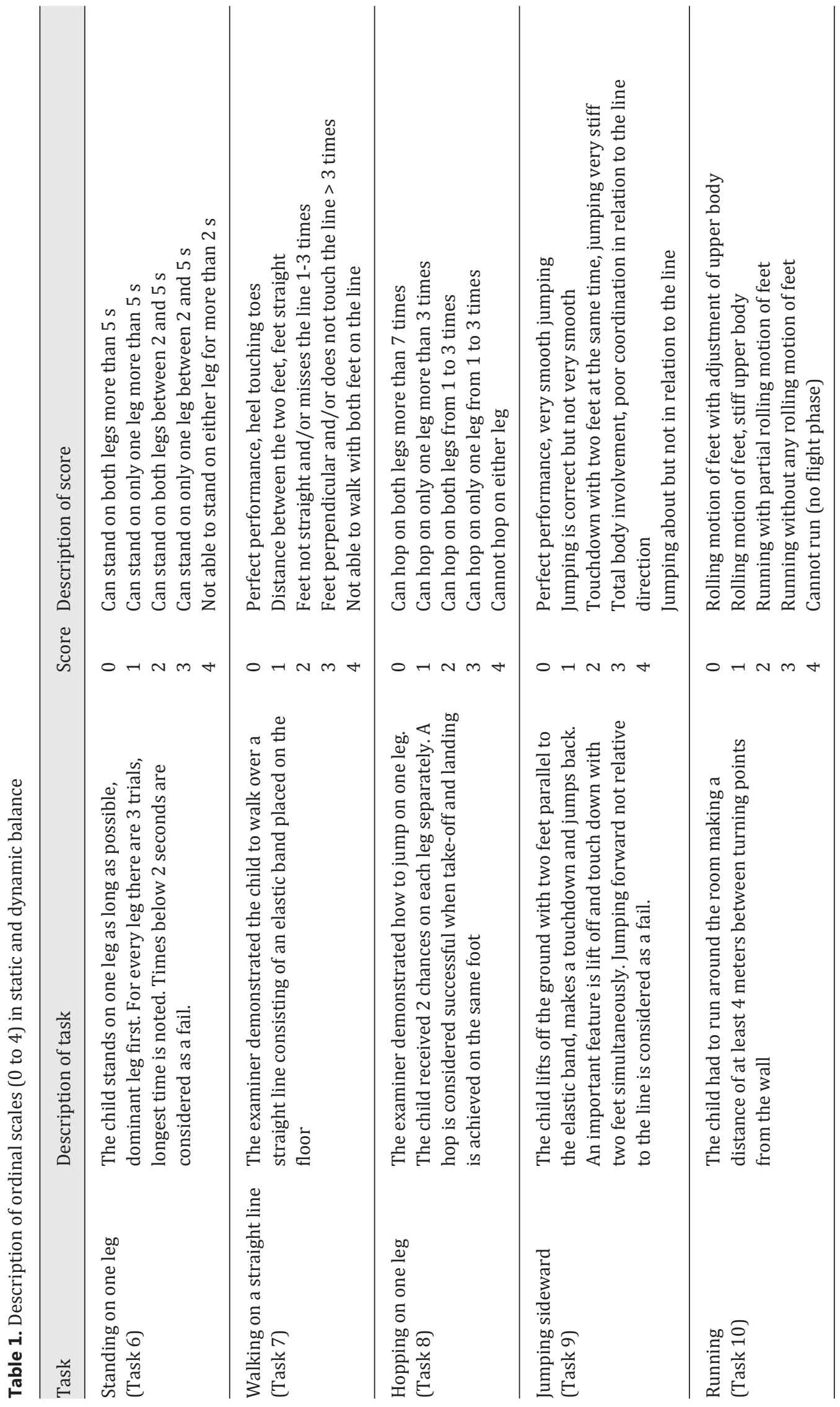


Table 2. Descriptive characteristics of the sample

Kakebeeke et al.: Association between Body Composition and Motor Performance in Preschool Children

\begin{tabular}{|c|c|c|}
\hline Characteristics & $\mathrm{N}$ & $\begin{array}{l}\text { Measures, } \\
\text { means } \pm \text { SD or } \%\end{array}$ \\
\hline Age, years & 476 & $3.9 \pm 0.7$ \\
\hline Boys & 251 & $53 \%$ \\
\hline Girls & 225 & $47 \%$ \\
\hline $\begin{array}{l}\text { Socioeconomic/cultural } \\
\text { ISEI } \\
\text { French-speaking part } \\
\text { German-speaking part }\end{array}$ & $\begin{array}{l}437 \\
123 \\
353\end{array}$ & $\begin{array}{l}61.8 \pm 15.9 \\
26 \% \\
74 \%\end{array}$ \\
\hline $\begin{array}{l}\text { Body composition } \\
\text { Skinfold thickness, } \mathrm{mm} \\
\text { Waist circumference, } \mathrm{cm} \\
\text { BMI, kg/m² } \\
\text { Overweight* } \\
\text { Obese* } \\
\text { Overweight } \\
\text { Obese }^{\#}\end{array}$ & $\begin{array}{l}428 \\
458 \\
463 \\
82 \\
24 \\
40 \\
10\end{array}$ & $\begin{array}{l}26.0 \pm 5.5 \\
51.9 \pm 3.5 \\
16.0 \pm 1.4 \\
17.7 \% \\
5.2 \% \\
8.6 \% \\
2.2 \%\end{array}$ \\
\hline $\begin{array}{l}\text { Physical activity } \\
\text { Total physical activity, cpm }\end{array}$ & 434 & $621.5 \pm 153.6$ \\
\hline $\begin{array}{l}\text { Fine motor tasks } \\
\text { Pegboard, s } \\
\text { Repetitive finger movement, s } \\
\text { Sequential finger movement, s } \\
\text { Repetitive hand movement, s } \\
\text { Alternating hand movement, s }\end{array}$ & $\begin{array}{l}428 \\
381 \\
368 \\
400 \\
378\end{array}$ & $\begin{array}{l}52.4 \pm 18.5 \\
5.0 \pm 1.6 \\
3.2 \pm 0.7 \\
4.6 \pm 1.2 \\
6.3 \pm 3.2\end{array}$ \\
\hline $\begin{array}{l}\text { Gross motor tasks } \\
\text { Standing on one leg, s } \\
\text { Walking on a straight line } \\
\text { Jumping sideward } \\
\text { Hopping on one leg } \\
\text { Ho } \\
\text { Running }\end{array}$ & $\begin{array}{l}398 \\
406 \\
391 \\
364 \\
407\end{array}$ & $\begin{array}{l}6.0 \pm 7.7 \\
2.2 \pm 0.8 \\
2.6 \pm 1.0 \\
2.4 \pm 1.4 \\
2.4 \pm 0.8\end{array}$ \\
\hline $\begin{array}{l}\text { cpm = Counts per minute. } \\
{ }^{*} \text { According to WHO criteria [17 } \\
{ }^{\#} \text { According to IOTF criteria }[17,\end{array}$ & & l \\
\hline
\end{tabular}

combination. An additional multilevel model analysis, which also includes height as a covariate, was also run for BMI by outcome combination. The obtained results were similar to those of the other models and, therefore, were not presented. All outcomes were tested for normal distribution, and none had to be transformed. Statistical significance was set at $\alpha=0.05$ for all analyses.

\section{Results}

The descriptive characteristics of the sample and the raw values of the ZNA are shown in table 2. Skinfold thickness was significantly correlated with $\mathrm{WC}(\mathrm{N}=422, \mathrm{r}=0.58, \mathrm{p}<0.001)$ and BMI $(\mathrm{N}=425, \mathrm{r}=0.51, \mathrm{p}<0.001)$, and WC was significantly correlated with BMI $(\mathrm{N}=454$, $\mathrm{r}=0.63, \mathrm{p}<0.001)$.

The associations between measures of FM (i.e., skinfold thickness and WC) and ZNA are shown in table 3, and the associations between BMI and ZNA are shown in table 4 . 
Table 3. Associations between ZNA and body fatness measures (skinfold thickness and waist circumference $)^{\mathrm{a}}$
Table 4. Associations between ZNA and BMI ${ }^{\mathrm{a}}$
Kakebeeke et al.: Association between Body Composition and Motor Performance in Preschool Children

\begin{tabular}{|c|c|c|c|}
\hline \multirow[t]{2}{*}{ ZNA variables } & \multirow[t]{2}{*}{$\mathrm{N}$} & \multicolumn{2}{|l|}{ Skinfold thickness } \\
\hline & & $\beta$-coefficient $(95 \% \mathrm{CI})$ & $\mathrm{p}$ value \\
\hline \multicolumn{4}{|l|}{ Gross motor tasks } \\
\hline Dynamic balance & 286 & $-2.18(-4.27,-0.09)$ & 0.041 \\
\hline Walking on a straight line* & 333 & $-0.94(-2.72,0.83)$ & 0.30 \\
\hline Jumping sideward* & 321 & $-1.92(-3.63,-0.22)$ & 0.027 \\
\hline Hopping on one leg* & 297 & $-1.35(-3.12,0.41)$ & 0.13 \\
\hline Running* & 333 & $0.37(-1.10,1.83)$ & 0.63 \\
\hline Static Balance & 326 & $-0.69(-2.68,1.30)$ & 0.50 \\
\hline \multicolumn{4}{|l|}{ Fine motor tasks } \\
\hline Pegboard & 345 & $0.78(-1.16,2.71)$ & 0.43 \\
\hline \multirow[t]{3}{*}{ Pure motor } & 326 & $1.48(-0.64,3.61)$ & 0.17 \\
\hline & & \multicolumn{2}{|l|}{ Waist circumference } \\
\hline & & $\beta$-coefficient (95\% CI) & $\mathrm{p}$ value \\
\hline \multicolumn{4}{|l|}{ Gross motor tasks } \\
\hline Dynamic balance & 296 & $-1.75(-4.90,1.41)$ & 0.28 \\
\hline Walking on a straight line* & 345 & $-1.09(-3.80,1.61)$ & 0.43 \\
\hline Jumping sideward* & 330 & $-3.34(-5.98,-0.69)$ & 0.014 \\
\hline Hopping on one leg* & 309 & $-0.82(-3.48,1.83)$ & 0.54 \\
\hline Running* & 346 & $1.21(-1.01,3.43)$ & 0.28 \\
\hline Static balance & 336 & $-0.71(-3.75,2.33)$ & 0.65 \\
\hline \multicolumn{4}{|l|}{ Fine motor tasks } \\
\hline Pegboard & 361 & $1.06(-1.88,3.99)$ & 0.48 \\
\hline Pure motor & 338 & $2.36(-0.91,5.64)$ & 0.16 \\
\hline \multicolumn{4}{|c|}{$\begin{array}{l}\text { CI = Confidence interval. } \\
\text { aCoefficients were obtained from multilevel models and are adjusted } \\
\text { for children's age and sex, parental ISEI, sociocultural region of } \\
\text { Switzerland, and total physical activity. In the multilevel models, } \\
\text { outcomes variables (i.e., ZNA components) were multiplied by } 100 \text { for } \\
\text { better visual reading. All ZNA variables are reported as component. } \\
\text { *Based on SDS data (see statistical analysis). }\end{array}$} \\
\hline
\end{tabular}

\begin{tabular}{llll}
\hline ZNA variables & N & BMI & \\
\cline { 3 - 4 } & & $\beta$-coefficient $(95 \%$ CI) & p value \\
\hline Gross motor tasks & & & \\
Dynamic balance & 301 & $5.11(-3.26,13.47)$ & 0.23 \\
$\quad$ Walking on a straight line* & 350 & $0.44(-6.44,7.31)$ & 0.90 \\
$\quad$ Jumping sideward* & 336 & $0.13(-6.81,7.07)$ & 0.97 \\
$\quad$ Hopping on one leg* & 313 & $0.53(-6.80,7.86)$ & 0.89 \\
$\quad$ Running* & 352 & $9.12(3.56,14.68)$ & 0.001 \\
$\quad$ Static balance & 342 & $3.33(-4.92,11.58)$ & 0.43 \\
Fine motor tasks & & & \\
$\quad$ Pegboard & 367 & $-1.47(-9.07,6.13)$ & 0.70 \\
$\quad$ Pure motor & 343 & $3.51(-4.98,12.00)$ & 0.42 \\
\hline
\end{tabular}

${ }^{\mathrm{a} C o e f f i c i e n t s ~ w e r e ~ o b t a i n e d ~ f r o m ~ m u l t i l e v e l ~ m o d e l s ~ a n d ~ a r e ~ a d j u s t e d ~}$ for children's age and sex, parental ISEI, sociocultural region of Switzerland, and total physical activity. In the multilevel models, outcomes variables (i.e., ZNA components) were multiplied by 100 for better visual reading. All the ZNA variables are reported as component.

*Based on SDS data (see statistical analysis). 
Kakebeeke et al.: Association between Body Composition and Motor Performance in Preschool Children

As age, gender, ISEI, sociocultural region, and physical activity were always included in the analysis, reported associations between body composition and motor components were always adjusted for these covariates.

Skinfold thickness was inversely associated with the dynamic balance component (i.e., gross motor tasks; table 3 ). A $\beta$-coefficient of 0.0218 indicates that an increase of one unit (in our case $1 \mathrm{~mm}$ ) in skinfold thickness results in a change of -0.0218 units (in our case SDS) in the dynamic balance component score. Moreover, when the associations between skinfold thickness and ZNA were assessed for each single parameter of the dynamic balance component, skinfold thickness was also inversely associated with jumping sideward. There were no significant associations between skinfold thickness and either fine motor tasks or the static balance component (table 3).

There was no significant association between WC and either fine or gross motor components (table 3). However, when the associations between WC and ZNA were assessed for each single parameter of the dynamic balance component, WC was inversely associated with jumping sideward (table 3).

There was no significant association between BMI and either fine or gross motor components (table 4). However, when the associations between BMI and ZNA were assessed for each single parameter of the dynamic balance component, BMI was positively associated with running (table 4).

In all the components of the ZNA, the intra-class correlations across all outcomes were low (between 0.01 and 0.24 ), which means that the ZNA varied little among child care centers.

\section{Discussion}

This study showed that, in a healthy population of preschoolers with a low prevalence of obesity (around 2\%), body composition measures are related to particular gross motor tasks, especially the dynamic balance components. Indeed, skinfold thickness and WC were inversely related to jumping sideward, indicating that children with higher levels of FM were less proficient in this gross motor task. Additionally, BMI was positively related to running, suggesting that children with a higher BMI, albeit mostly within a normal range, had a higher running score on the ZNA. In this population, BMI may rather reflect FFM. On the other hand, there was no significant association between BMI, skinfold thickness, or WC measures and pegboard and pure motor components, suggesting that measures of body composition are not related to fine motor tasks.

Some studies have reported an inverse association between weight and motor performance in older children [34-39]. However, these results were inconclusive, and differences between groups were generally based on BMI. Some of these studies showed that obese children were better in some tasks, such as throwing performance $[40,41]$ and static balance [42]. Another study found a different impact of BMI on fine and gross motor skills [43]: only the gross motor skills were inversely related to BMI. Because BMI does not just reflect FM, especially early in the course of weight gain [18], it would be important to include more direct measures of body fat. For this reason, we decided also to measure skinfold thickness and WC in this study.

The association of body composition and motor performance has been evaluated in only two studies, which investigated school-age children. Okely et al. [5], who studied the associations between BMI, WC, and fundamental motor skills in children from grade 4 to 10 , showed that overweight children were less likely to have high levels of fundamental motor skills. The same finding was reported by Prskalo et al. [4] who showed that differences in motor performance between normal-weight, overweight, and obese children between 7 and 11 years 
Kakebeeke et al.: Association between Body Composition and Motor Performance in Preschool Children

(categories based on body fat measures) were attributed to those items of motor performance in which body weight has an impact on the efficient execution of movement.

Our results revealed significant inverse associations between skinfold thickness or WC and jumping sideward. Both measures focus on the measurement of body fat, and therefore high values indicate a higher percentage of FM $[15,21,44]$. It seems obvious that having more FM does not help a child in motor activities that involve changes in center of mass. The idea that carrying too much weight may have such an effect was termed the morphological constraint hypothesis coined by Chivers et al. [42].

The morphological constraint hypothesis states that children who are overweight or obese have to move within high biomechanical constraints and are therefore more challenged in tasks that involve changes in center of mass. Indeed, we did not find any impact of weight on fine motor skills (which do not involve changes in center of mass), but only on gross motor skills. However, if the morphological constraint hypothesis was consistent, one would expect that having more FM would also have a significant negative effect on hopping on one leg in addition to jumping sideward, which was not found in this study. The associations of skinfold thickness $(p=0.13)$ and WC ( $p=0.54)$ with hopping on one leg were negative, but not significant.

Jumping sideward is an exercise against gravity that might have been too difficult for preschool children. Thus, the effect of weight could not be disentangled from the coordinative demands imposed by the task. The importance of age, and therefore of time for development, was indicated by Prskalo et al. [4] who did not find a difference in motor skills between normal-weight and overweight children in 7- to 9-year-old boys. The authors stated that motor skills were not sufficiently developed in their participants to show the effect of weight on test performance [4].

In the current study, an inverse association of body composition was only found with jumping sideward, but not with jumping on one leg. In both tasks, the center of mass has to be moved against gravity. However, for jumping sideward the child needs to move his body not only against gravity but also in relation to a line. The perceptual constraint added by the line is more influential in this task and includes a visual component. A study on gait control in obese and normal-weight children investigated the effect of vision in children in their early teens [45]. The obese children were more dependent on vision than the normal-weight children. The authors concluded that the obese children not only suffer from the mechanical problem of moving excess of mass butalso seem to have a different linkage between perception and action, which leads to a poorer motor performance. D'Hondt et al. [45] hypothesized that the reason for this is that sensory information is processed differently in obese children when controlling locomotion.

The effect of body mass on motor planning and skills was also studied in experiments examining obstacle crossing through 3D kinematics and kinetics [46]. The results showed that the obese children had more difficulty in motor planning and motor skills, as their strategy left them less stable after crossing the obstacles. The difficulty that obese children experience in planning and controlling their additional weight seems obvious to Gill et al. [46]. However, other processes responsible for motor skill abilities, such as changes in spatial and visual perception, were proposed as causes for the differences between groups [46].

In the light of these two studies $[45,46]$, it seems that the challenge of having more weight in our demanding perceptual and coordinative task, jumping sideward, leads to an interaction. Jumping sideward was more difficult for those children with an excess of body fat because it also involved coordinative challenges.

Our results showed that BMI was positively associated with running, because children with a higher BMI had a higher running score on the ZNA. Higher BMI is assumed to be a good indicator of excess body fat in children, but among normal-weight young children increased 
BMI can be mainly related to an increase in FFM rather than FM [18]. In the present study, children were predominantly normal-weight, and the prevalence of obesity was very low. Therefore, one can suggest that overall the preschool population with higher BMI may have more FFM, which probably results in better running performance. This hypothesis is supported by the fact that we did not find the same results for running when we used more direct measures of body fat. Interestingly, it has recently been suggested that the prevalence of overweight and obesity in schoolchildren may be twofold higher using WHO compared to IOTF criteria [47]. The results of the current study in young preschoolers support these observations (table 2). A limitation of this study is that we did not investigate how body composition measures are related to the awareness of space or spatial perception of the body in this cohort. Tests that focus on the relationship between perceived motor competence and motor proficiency should be also considered in future studies [12]. A strength of SPLASHY is that we examined the relationship between body composition and both gross and fine motor tasks in a large population of 2- to 6-year-old children. Regarding multiple testing, we performed a total of 24 analyses (eight predictors $\times$ three outcomes). Of these, four were significant, which is about 3.3 times as high as the $1.2(=24 \times 0.05)$ cases that one would expect by chance for $\alpha=0.05$, assuming independent analyses.

In conclusion, in a large sample of predominantly normal-weight young preschoolers, associations between body composition and motor performance were only observed for gross motor tasks, but not for fine motor tasks. We found inverse associations between skinfold thickness and WC and jumping sideward, suggesting that children with more FM are more challenged in this perceptually demanding task. On the other hand, the positive association between BMI, but not body fat measures, and running abilities underlines the hypothesis that BMI is probably a marker of FFM in these healthy preschoolers rather than of excess FM.

\section{Authors' Contributions}

TK and SL wrote the paper. AZ, AA, KS, CL, EA, TK, and NM collected the data. SL, NM, and AM performed statistics. JP, SM, SK, and OJ designed the study. All co-authors approved the final version of the manuscript.

\section{Acknowledgments}

We would like to thank all children, families and child care centers that contributed data to SPLASHY. We also thank all students and the research team for their valuable contribution. The study was funded through a Sinergia grant from the Swiss National Research Foundation (SNF, Number: CRSII3_147673), the Jacobs Foundation, and the Majores Foundation.

\section{Disclosure Statement}

The authors have no conflict of interest to disclose.

\section{References}

1 Newell K: Constraints on the development of coordination; in Wade MG, Whiting HT (eds): Motor Development in Children: Aspects of Coordination and Control. Dordrecht, Nijhoff, 1986.

2 Levtzion-Korach 0, Tennenbaum A, Schnitzer R, Ornoy A: Early motor development of blind children. J Paediatr Child Health 2000;36: 226-229.

3 Gheysen F, Loots G, Van Waelvelde H: Motor development of deaf children with and without cochlear implants. J Deaf Stud Deaf Educ, 2008;13:215-224. 
Kakebeeke et al.: Association between Body Composition and Motor Performance in Preschool Children

4 Prskalo I, Badric M, Kunjesic M: The percentage of body fat in children and the level of their motor skills. Coll Antropol 2015;1:21-28.

5 Okely AD, Booth ML, Chey T: Relationships between body composition and fundamental movement skills among children and adolescents. Res Q Exerc Sport 2004;75:238-247.

6 Metcalf BS, Hosking J, Jeffer AN,Voss LD, Henley W, Wilkin TJ: Fatness leads to inactivity, but inactivity does not lead to fatness: a longitudinal study in children (EarlyBird 45). Arch Dis Child 2011;96:942-947.

7 Magill RA: Motor Learning: Concepts and Applications, 4th ed. Dubuque, Brown \& Benchmark, 1993.

8 Kottke FJ: From reflex to skill: the training of coordination. Arch Phys Med Rehab 1980;61:551-561.

9 Goodway JD; Branta CF: Influence of a motor skill intervention on fundamental motor skill development of disadvantaged preschool children. Res Q Exerc Sport 2003;74:36-46.

10 Wrotniak BH, Epstein LH, Dorn JM, Jones KE, Kondilis VA: The relationship between motor proficiency and physical activity in children. Pediatrics 2006;118:e1758-1765.

11 Williams HG, Pfeiffer KA, O’Neill JR, Dowda M, McIver KL, Brown WH, Pate RR: Motor skill performance and physical activity in preschool children. Obesity (Silver Spring) 2008:16:1421-1426.

12 Stodden DF, Goodway JD, Langendorfer SJ, Roberton MA, Rudisill ME, Garcia C, Garcia LE: A developmental perspective on the role of motor skill competence in physical activity: an emergent relationship. Quest 2008; 60:290-306.

13 Largo RH, Rousson V, Caflisch JA, Jenni OG: Zurich Neuromotor Assessment. Zurich, AWE Verlag, 2007.

14 Kakebeeke TH, Caflisch J, Chaouch A, Rousson V, Largo RH, Jenni OG: Neuromotor development in children. Part 3: motor performance in 3- to 5-year-olds. Dev Med Child Neurol 2013;55:248-256.

15 Duren DL, Sherwood RJ, Czerwinski SA, Lee M, Choh AC, Siervogel RM, Cameron Chumlea W: Body composition methods: comparisons and interpretation. J Diabetes Sci Technol 2008;2:1139-1146.

16 Heymsfield SB, Lohmann T, Wang Z, Going SB: Human Body Composition. Champaign, Human Kinetics Press, 2005.

17 WHO Multicentre Growth Reference Study Group: WHO child growth standards based on length/height, weight and age. Acta Paediatr Suppl 2006;450:76-85.

18 Freedman DS, Sherry B: The validity of BMI as an indicator of body fatness and risk among children. Pediatrics 2009;124(suppl 1):S23-34.

19 Cole TJ, Flegal K, Dietz WH: Detecting obesity based on skinfold thicknesses. Am J Clin Nutr 2005;81:196; author reply 196-197.

20 Taylor RW, Jones IE, Williams SM, Goulding A: Evaluation of waist circumference, waist-to-hip ratio, and the conicity index as screening tools for high trunk fat mass, as measured by dual-energy X-ray absorptiometry, in children aged 3-19 y. Am J Clin Nutr 2000;72:490-495.

21 Boeke CE, Oken E, Kleinman KP, Rifas-Shiman SL, Taveras EM, Gillman MW: Correlations among adiposity measures in school-aged children. BMC Pediatr 2013;13:99.

22 Wohlfahrt-Veje C, Tinggaard J, Winther K, Mouritsen A, Hagen CP, Mieritz MG, de Renzy-Martin KT, Boas M, Petersen JH, Main KM: Body fat throughout childhood in 2647 healthy Danish children: agreement of BMI, waist circumference, skinfolds with dual X-ray absorptiometry. Eur J Clin Nutr 2014;68:664-670.

23 Wang Y. Lim H: The global childhood obesity epidemic and the association between socio-economic status and childhood obesity. Int Rev Psychiatry 2012;24:176-188.

24 Bonvin A, Barral J, Kakebeeke TH, Kriemler S, Longchamp A, Marques-Vidal P, Puder JJ: Weight status and gender-related differences in motor skills and in child care - based physical activity in young children. BMC Pediatr 2012;12:23.

25 Burgi F, Meyer U, Niederer I, Ebenegger V, Marques-Vidal P, Granacher U, Kriemler S, Puder JJ: Socio-cultural determinants of adiposity and physical activity in preschool children: a cross-sectional study. BMC Public Health 2010;10:733.

26 Messerli-Bürgy N, Kakebeeke TH, Arhab A, Stülb K, Zysset AE, Leeger-Aschmann CS, Schmutz EA, Fares F, Meyer AH, Munsch S, Kriemler S, Jenni OG, Puder JJ: The Swiss Preschoolers' health study (SPLASHY): objectives and design of a prospective multi-site cohort study assessing psychological and physiological health in young children. BMC Pediatr 2016;16:85.

27 Cole TJ, Bellizzi MC, Flegal KM, Dietz WH: Establishing a standard definition for child overweight and obesity worldwide: international survey. BMJ 2000;320:1240-1243.

28 Kakebeeke TH, Egloff K, Caflisch J, Chaouch A, Rousson V, Largo RH, Jenni OG: Similarities and dissimilarities between the Movement ABC-2 and the Zurich Neuromotor Assessment in children with suspected developmental coordination disorder. Res Dev Disabil 2014;35:3148-3155.

29 Largo RH, Caflisch JA, Hug F, Muggli K, Molnar AA, Molinari L, Sheehy A, Gasser ST: Neuromotor development from 5 to 18 years. Part 1: timed performance. Dev Med Child Neurol 2001;43:436-443.

30 Largo RH, Caflisch JA, Hug F, Muggli K, Molnar AA, Molinari L, Sheehy A, Gasser ST: Neuromotor development from 5 to 18 years. Part 2: associated movements. Dev Med Child Neurol 2001;43:444-453.

31 Ganzeboom HBG, Degraaf PM, Treiman DJ, Deleeuw J: A standard international socioeconomic index of occupational status. Soc Sci Res 1992;21:1-56.

32 Gasser T, Rousson V: Modelling neuromotor ratings with floor-effects. Stat Med 2004;23:3641-3653.

33 Jenni OG, Chaouch A, Caflisch J, Rousson V: Correlations between motor and intellectual functions in normally developing children between 7 and 18 years. Dev Neuropsychol 2013;38:98-113. 
Kakebeeke et al.: Association between Body Composition and Motor Performance in Preschool Children

34 D'Hondt E, Deforche B, De Bourdeaudhuij I, Lenoir M: Childhood obesity affects fine motor skill performance under different postural constraints. Neurosci Lett 2008;440:72-75.

35 D’Hondt E, Deforche B, Gentier I, Verstuyf J, Vaeyens R, De Bourdeaudhuij I, Philippaerts R, Lenoir M: A longitudinal study of gross motor coordination and weight status in children. Obesity (Silver Spring) 2014;22: 1505-1511.

36 D'Hondt E, Deforche B, Vaeyens R, Vandorpe B, Vandendriessche J, Pion J, Philippaerts R, de Bourdeaudhuij I, Lenoir M: Gross motor coordination in relation to weight status and age in 5- to 12-year-old boys and girls: a cross-sectional study. Int J Pediatr Obes 2011;6:e556-564.

37 Mond JM, Stich H, Hay PJ, Kraemer A, Baune BT: Associations between obesity and developmental functioning in pre-school children: a population-based study. Int J Obes (Lond) 2007;31:1068-1073.

38 Krombholz H: Motor and cognitive performance of overweight preschool children. Percept Mot Skills 2013; 116:40-57.

39 Logan,SW, Robinson LE, Getchell N: The comparison of performances of preschool children on two motor assessments. Percept Mot Skills 2011;113:715-23.

40 Morano M, Colella D, Robazza C, Bortoli L, Capranica L: Physical self-perception and motor performance in normal-weight, overweight and obese children. Scand J Med Sci Sports 2011;21:465-473.

41 De Toia D, Klein D, Weber S, Wessely N, Koch B, Tokarski W, Dordel S, Struder H, Graf C: Relationship between anthropometry and motor abilities at pre-school age. Obes Facts 2009;2:221-225.

42 Niederer I, Kriemler S, Zahner L, Burgi F, Ebenegger V, Marques P, Puder JJ: BMI group-related differences in physical fitness and physical activity in preschool-age children: a cross-sectional analysis. Res Q Exerc Sport 2012;83:12-19.

43 Chivers P, Larkin D, Rose E, Beilin L, Hands B: Low motor performance scores among overweight children: poor coordination or morphological constraints? Hum Mov Sci 2013;32:1127-1137.

44 McCarthy HD, Cole TJ, Fry T, Jebb SA, Prentice AM: Body fat reference curves for children. Int J Obes (Lond) 2006;30:598-602.

45 D’Hondt E, Segers V, Deforche B, Shultz SP, Tanghe A, Gentier I, De Bourdeaudhuij I, De Clercq D, Lenoir M: The role of vision in obese and normal-weight children's gait control. Gait Posture 2011,33.179-!84.

46 Gill SV, Hung YC: Effects of overweight and obese body mass on motor planning and motor skills during obstacle crossing in children. Res Dev Disabil 2014;35:46-53.

47 Keke LM, Samouda H, Jacobs J, di Pompeo C, Lemdani M, Hubert H, Zitouni D, aGuinhouya BC: Body mass index and childhood obesity classification systems: a comparison of the French, International Obesity Task Force (IOTF) and World Health Organization (WHO) references. Rev Epidemiol Sante Publique 2015;63:173-182. 